\title{
Contribuciones de Wilhelm His a la Embriología Humana
}

\author{
Contributions of Wilhelm His to Human Embryology
}

Godoy-Guzmán, C.

GODOY-GUZMAN, C. Contribuciones de Wilhelm His a la embriología humana. Int. J. Morphol., 31(1):70-74, 2013.

RESUMEN: Wilhelm His (1831-1904) gran anatomista y embriólogo suizo, profesor de la cátedra de anatomía de la Universidad de Basilea y Universidad de Leipzig. His, realizó el primer intento de estudiar los distintos estadios del embrión humano en su totalidad. Para tal fin, introdujo importantes avances tecnológicos que permitieron una comprensión más detallada del embrión humano, marcando un hito en el desarrollo de la embriología como ciencia. En este trabajo se resumen las principales contribuciones de Wilhelm His en el campo de la embriología humana. Uno de sus principales aportes fue la invención del micrótomo en 1866, el cual permitió reconstruir el embrión a partir de secciones histológicas. Otro de sus grandes inventos fue el denominado embriógrafo, instrumento que posibilitó la visualización de cortes histológicos en bajos aumentos y su reconstrucción sobre un papel. Además, fue pionero en intentar seleccionar los embriones humanos colectados presumiblemente en orden de su desarrollo. Dividió el desarrollo humano en estadios, estableciendo normas a partir de las relaciones entre forma y tamaño característicos de cada estadio. Gran parte de sus descubrimientos sobre el desarrollo del embrión humano se encuentran plasmados en el trabajo titulado Anatomie der Menschlichen Embryonen (18801885). La noble tarea de dilucidar la anatomía del embrión humano fue posible gracias este conjunto de innovaciones tecnológicas y metodológicas y su perseverante trabajo. Debido a sus grandes aportes en el campo de la embriología se le confiere el nombre de "Vesalius de la embriología humana".

PALABRAS CLAVE: Wilhelm His; Embriología humana; Historia

\section{INTRODUCCIÓN}

Wilhelm His nació el 9 de Julio de 1831 en Basilea, Suiza, en el seno de una familia muy acomodada (Fig. 1). En lo que respecta a su formación médica tuvo la oportunidad de colaborar con los mejores profesores y científicos de su época. Inicia sus estudios de medicina en Basilea y luego los continúa en Berna. Años más tarde, se traslada a Berlín para el estudio de la anatomía con Johannes Müller y de la embriología con Robert Remak, uno de los más célebres embriólogos de la época (Peipert \& Roberts, 1986; Loukas et al., 2008). Posteriormente, viaja a Würzburg a trabajar con Rudolf Virchow, científico que tuvo una gran influencia sobre él. En 1854 retorna a Basilea donde obtuvo su título de médico graduándose con honores. En su tesis abordó la anatomía y patología de la córnea, tema en el que fue introducido por su amigo y mentor Rudolf Virchow (Anónimo, 1964).

Los 3 años posteriores a su graduación como médico se dividieron en un continuo peregrinar entre diferentes laboratorios de investigación y hospitales de Europa. En 1856 viaja a Berlín donde colabora en los trabajos de Theodor Billroth centrados en el tejido linfático y conectivo (Loukas et al.). En 1857 es nombrado profesor de la cátedra de anatomía en la Universidad de Basilea a la edad de 26 años (Anónimo). Durante los años siguientes publica toda una serie de trabajos sobre embriología e histología. En 1865 publica su famoso tratado "On the tissue-layers and spaces of the body" (His, 1865).

En 1872 asume el cargo de profesor de anatomía en la Universidad de Leipzig donde permanece por el resto de su carrera. En 1876 se convierte en miembro fundador del Journal of Anatomy and development. Es en este periodo donde His crea la ciencia de la histogénesis y embriología comparada a partir de su perseverante trabajo científico e innovaciones tecnológicas.

His, fue uno de los fundadores de la Anatomichen Gessellschaft en 1886, así como también uno de los creadores de la International Commission for Anatomical Terminology en 1895, cuyo objetivo fue el de unificar la nomenclatura anatómica y estandarizar su uso en la comunidad científica (His, 1895; Loukas et al.). 


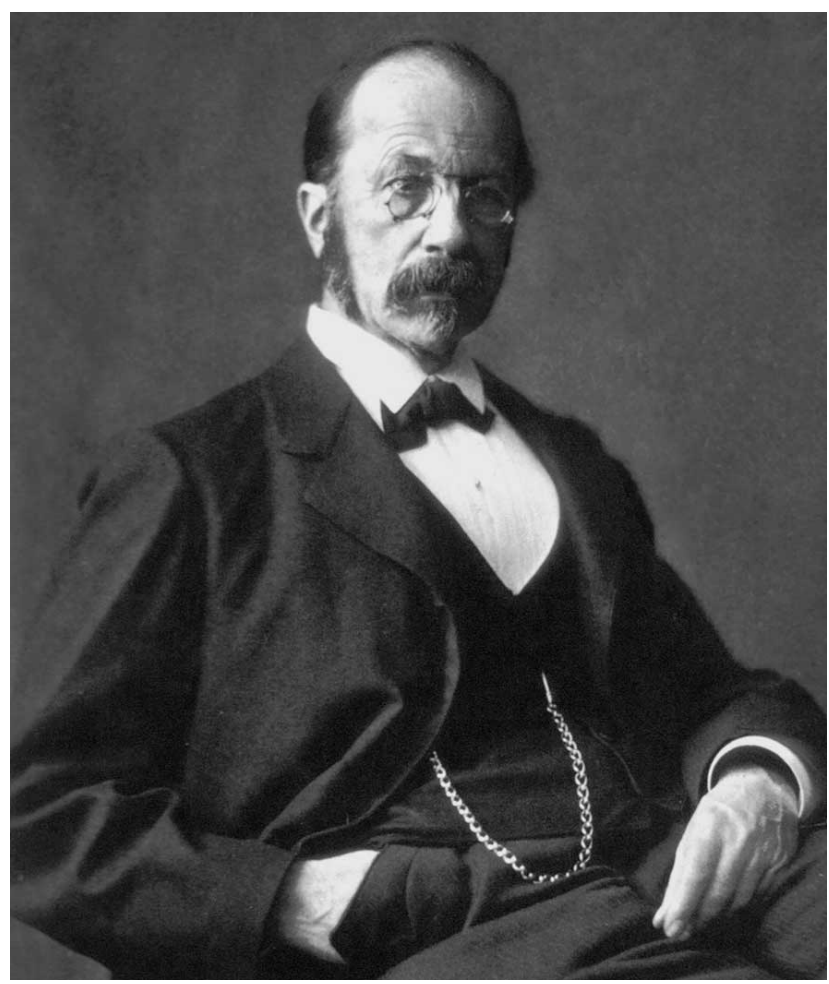

Fig. 1. Fotografía del Profesor Wilhelm His tomada por Nicola Perscheid.

En 1894 el multifacético His se embarca en la búsqueda e identificación de los restos de Johann Sebastian Bach. Todo comenzó cuando en octubre de 1884 fue encontrado un ataúd en el patio de la vieja iglesia Johanniskirche, el cual contenía el esqueleto de "un hombre de edad avanzada, no muy alto". His, a través de un cuidadoso examen, determinó que el esqueleto no correspondía al de un hombre común y corriente, sino que con toda probabilidad correspondía al esqueleto de Bach. His contrató a un escultor para moldear un busto de yeso a partir del cráneo encontrado, una vez terminada la figura, el busto se asemejaba de gran manera a la fisonomía del famoso compositor de música. Posteriormente, His y el experto en otología, el profesor Adam Politzer, investigaron cuidadosamente el esqueleto encontrado. Dentro de los hallazgos más importantes observaron un hueso temporal particularmente pronunciado, así como un enrollamiento de la cóclea más largo de lo habitual. Postulando que estos hallazgos sólo pueden estar relacionados con la figura del gran compositor Johann Sebastian Bach (Peipert \& Roberts).

Cabe destacar la gran influencia que tuvo Wilhelm His sobre su amigo y admirador Franklin Mall en la fundación del departamento de embriología de la Carnegie Institution en Washington DC en 1913, uno de los centros de investigación embriológica más importantes en el mundo (Mall, 1905, 1914).
La familia His realizó grandes aportes en el campo de la embriología, histología y electrofisiología. En este sentido destacan los trabajos de su hijo llamado Wilhelm His (1863-1934) quien publicó un artículo de 35 páginas, donde describe la actividad del corazón del embrión y la importancia de su compresión para entender la actividad del corazón adulto. Sin embargo, sólo una página de este trabajo está dedicada a uno de sus descubrimientos más conocidos, el haz de His (Roguin, 2006).

Descubriendo la anatomía del embrión humano. En 1878 Wilhelm His se embarca en el mayor estudio del desarrollo embrionario humano desde Samuel Thomas Soemmerring en 1799. Para tal estudio fue necesario comenzar un largo proceso de colecta de embriones y fetos provenientes desde diversos orígenes tales como: abortos espontáneos, abortos provocados, colecciones pertenecientes a museos y muy ocasionalmente desde mujeres embarazadas post-mortem (Hopwood, 2000). Sin embargo, el proceso de recolección no fue una tarea fácil, especialmente el obtener los embriones más tempranos.

His debió innovar en los métodos de conservación del material colectado, así como también en su forma de transporte al laboratorio. En primer lugar, fijó la muestra en alcohol para evitar los cambios celulares post-mortem, lo que permitió preservar en términos generales la morfología y la composición química de las células y los tejidos. En segundo lugar, procedió a la disección de las muestras, removiendo el corion y el amnios, para así tener acceso al preciado embrión. Finalmente, determinó la normalidad o anormalidad del embrión a través del análisis morfológico externo. Si el embrión era considerado normal, se procedió a su estudio morfológico detallado a través de diversas técnicas.

His, en una carta escrita al médico Fiedrich Miescher para agradecer su hospitalidad durante su estadía en Basilea el verano de 1878, describe en términos generales el trabajo investigativo efectuado a partir de un embrión humano (Hopwood): "En las últimas semanas mi gratitud tiene relación con un objeto muy concreto, con él que me he ocupado intensamente, dibujando, fotografiando, midiendo y cortando a través de microtomía. Como puedes ver, trabajando durante este tiempo en un pequeño embrión, el cual tú me diste para la colección hace algunos años atrás. Kollmann fue tan amable como para dejarme trabajar en él, ya que a pesar del tiempo que ha estado en alcohol sigue siendo muy útil, logré una buena comprensión de su exterior e interior. He enviado a Kollmann algunas fotografías y un modelo de cera pequeño, el primer fruto de mis esfuerzos. Aparte de esto..., he tenido la suerte este otoño de tener en mis manos algunas pequeñas personas más, por lo que este invierno estaré ricamente suministrado con material para poder trabajar". 
Además, His realizó el primer intento de seleccionar los embriones humanos colectados presumiblemente en orden de su desarrollo. Dividió el desarrollo humano en estadios, estableciendo normas a partir de las relaciones entre forma y tamaño característicos de cada estadio (His, 1880; 1882). El reflejo de este trabajo se puede observar en la composición de la clasificación denominada "Normentafel" (placa de normas) (Fig. 2). Esta litografía consiste en 25 dibujos que ilustran las características morfológicas externas del embrión desde el término de la segunda semana hasta ocho semanas post fecundación aproximadamente. Sin embargo, según O'Rahilly \& Müller (1988), los principios utilizados en esta clasificación tienen algunas limitaciones como: primero, que los embriones no pueden ser clasificados en series perfectas, ya que un especimen puede estar más avanzado en un aspecto, mientras que en otro puede estar retardado. Segundo, puede resultar imposible que coincida un nuevo embrión (por clasificar) con las normas ilustradas (Fig. 2).

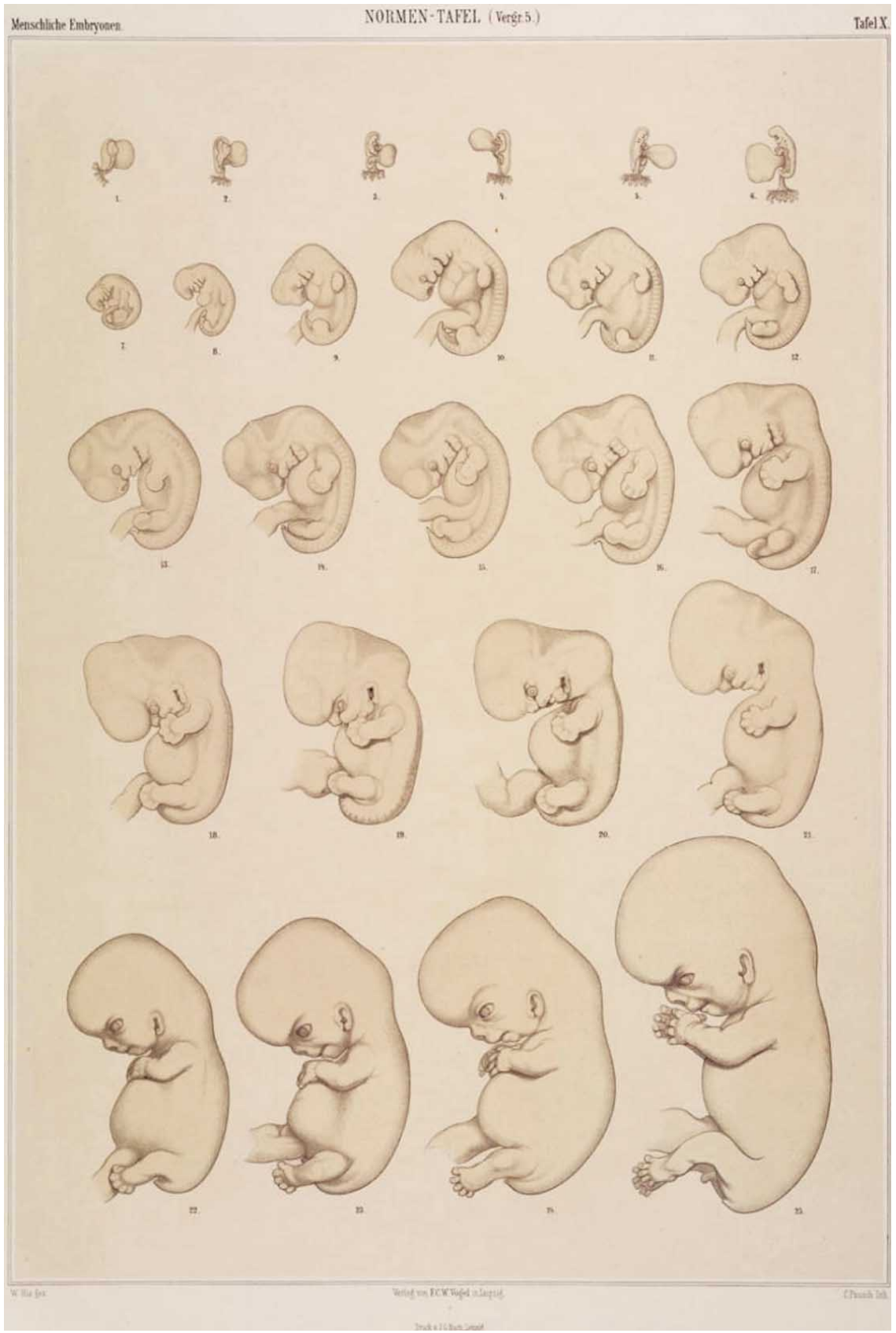

Fig. 2. Normentafel. Litografía que ilustra los diferentes estadios del desarrollo embrionario humano. Wilhelm His divide el desarrollo embrionario normal en diferentes estadios de acuerdo a las relaciones de forma y tamaño. Tomada desde His (1885).
En 1866 His inventa el micrótomo, este instrumento permitió la obtención de delgadas secciones histológicas, a partir de las cuales es posible observar la estructura de los tejidos a través del microscopio (Roguin; His, 1870). La invención del micrótomo marca una verdadera revolución en el campo de la embriología, ya que permitió la reconstrucción de los diversos sistemas del embrión a partir de secciones histológicas. Estas reconstrucciones se vieron reflejadas en la elaboración de modelos de cera, que permitieron una mejor comprensión de los procesos de organogénesis y morfogénesis que ocurren durante el periodo embrionario. Posteriormente en 1887, His construye un instrumento que consiste en la combinación de la cámara lucida (cámara Oberhauser) con el microscopio (Fig. 3). A este instrumento se le denominó Zeichnungsapparat o embriógrafo y permitió la visualizacion de cortes histológicos en bajos aumentos y su reconstrucción sobre un papel (His, 1880). Este conjunto de innovaciones tecnológicas marcan un antes y un después en la ciencias morfológicas, ya que permiten por primera vez un estudio detallado de la anatomía del embrión humano.

Gran parte de sus investigaciones sobre el desarrollo del embrión humano se encuentra plasmadas en el trabajo titulado Anatomie der menschlichen Embryonen publicado en 3 tomos (His, 1880, 1882, 1885). En este trabajo destacan descripciones detalladas del desarrollo de sistemas tales como: 


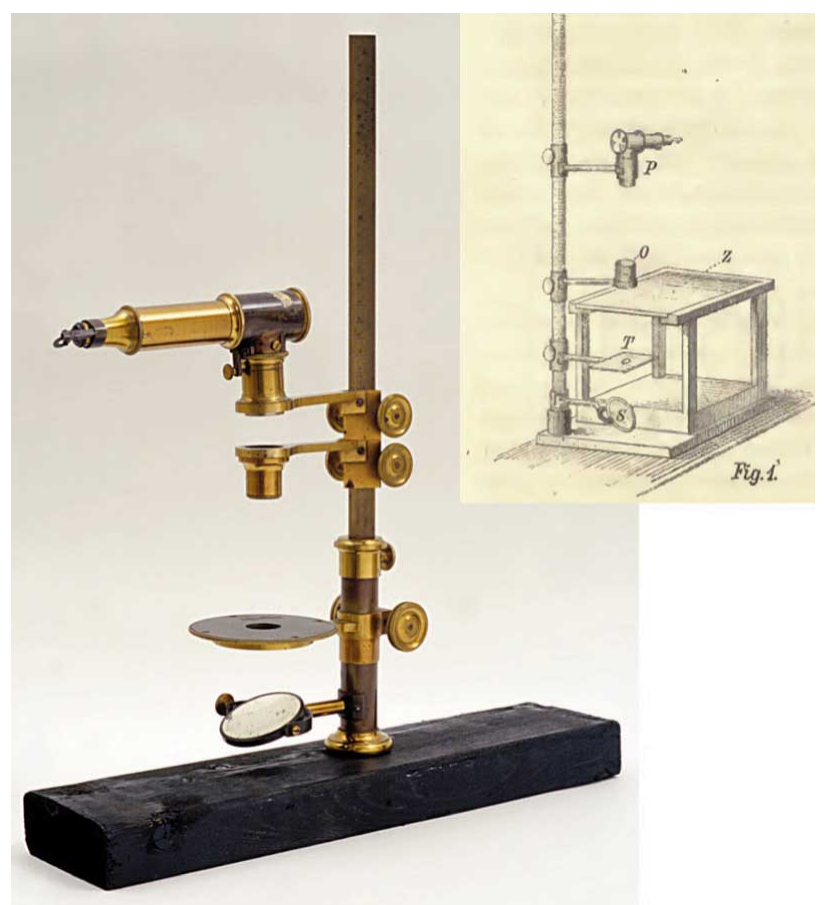

Fig. 3. Embriógrafo. Este instrumento consiste en una combinación entre el microscopio y la cámara lúcida. Su función es permitir la visualización de cortes histológicos en bajos aumentos y su reconstrucción sobre un papel. Historical Collections, National Museum of Health and Medicine, Armed Forces Institute of Pathology, Washington D.C (Buklijas \& Hopwood, 2008-2010).

- Sistema respiratorio: Describió el proceso de ramificación del árbol bronquial a partir de las 2 yemas pulmonares desde el día 30 al 50 post-fecundación aprox.

- Sistema cardiovascular: Describió el desarrollo del septum interatrial, del septum interventricular y el proceso de formación de la aorta y arteria pulmonar a partir del tronco arterioso. Además, His introduce el término de endotelio.

- Sistema Nervioso: Realizó una descripción detallada del desarrollo del cerebro durante el periodo embrionario. Además, introduce el término de dendritas (Roguin).

- Desarrollo de la cara: Describió el proceso de formación de la cara a partir de diversas estructuras conocidas actualmente como: Prominencia fronto-nasal, procesos maxilares, procesos nasales mediales y laterales y procesos mandibulares.

Wilhelm His muere el 1 de mayo 1904 mientras trabajaba como profesor en la Universidad de Leipzig. La noble tarea de dilucidar la anatomía del embrión humano fue posible gracias a la invención del micrótomo y embriógrafo, la reconstrucción a partir de secciones histológicas, el mejoramiento de las técnicas de fijación y su perseverante trabajo. El lema de toda su vida fue "que el progreso en la anatomía es más probable que ocurra cuando sus problemas incluyan el estudio del crecimiento y la función, así como de la estructura" (Loukas et al.). Debido a sus grandes aportes en el campo de la embriología se le confiere el nombre del "Vesalius de la embriología humana" (O'Rahilly \& Müller).

\section{AGRADECIMIENTOS}

Doy las gracias a la Prof. Fabiola Flores-Cruz, Universidad de Chile y Prof. Pablo Nova, Unidad de Anatomía Normal, Universidad de Santiago de Chile por el análisis crítico de este manuscrito. Este trabajo fue patrocinado por DICYT (Universidad de Santiago de Chile, Santiago, Chile; Grant no. 021001GG).

GODOY-GUZMAN, C. Contributions of Wilhelm His to human embryology. Int. J. Morphol., 31(1):70-74, 2013.

SUMMARY: Wilhelm His (1831-1904), a great Swiss anatomist and embryologist, professor of anatomy at the university of Basel and the university of Leipzig. His, made the first attempt to study the different stages of the total human embryo. For that purpose he introduced important technological advances that allowed a more detailed understanding of the embryo, setting a landmark in the development of embryology as a science. This paper summarizes the main contributions of Wilhelm His in the field of human embryology. One of his major contributions was the invention of the microtome en 1866, which allowed the reconstruction of the embryo from histological sections. Another one of his great inventions was the so-called embryograph, an instrument that allows viewing histological sections at low magnification and reconstructing them on paper. He was also a pioneer in attempting to select human embryos presumably collected in their order of development. He divided human development into stages, establishing standards from the relations between the shape and size characteristic of each stage. A large part of his discoveries on the development of the human embryo is found in his work titled Anatomie der Menschlichen Embryonen (1880-1885). The noble task of elucidating the anatomy of the human embryo was possible thanks to a set of technologicals and methodological innovations and his persevering work. Because of his great contributions in the field of embryology he is given the name of "Vesalius of human embryology".

KEY WORDS: Wilhelm His; Human embryology; History. 


\section{REFERENCIAS BIBLIOGRÁFICAS}

Anónimo. Wilhelm His Sr. (1831-1904) embryologist and anatomist. JAMA, 187:58, 1964.

Buklijas, T. \& Hopwood, N. Remodelling: Setting standards. Making Visible Embryos, 2008-2010. Disponible en: http:// www.hps.cam.ac.uk/visibleembryos/s5_2.html

His, W. Anatomical nomenclature. Leipzig, Veit \& Co., 1895.

His, W. On the tissue and spaces of the body. Basel, Schweihauser, 1865.

His, W. Anatomie menschlicher Embryonen, Vol. 1. Embryonen des ersten Monats. Leipzig, Vogel, 1880.

His, W. Anatomie menschlicher Embryonen. Vol. 2. Gestalt- und Grössenentwicklung bis zum Schluss des 2. Monats. Leipzig, Vogel, 1882.

His, W. Anatomie menschlicher Embryonen. Vol. 3. Zur Geschichte der Organe. Leipzig, Vogel, 1885.

His, W. Description of a microtome. Arch. Microskop. Anat., 6:22932,1870 .

Hopwood, N. Producing development: The anatomy of human embryos and the norms of Wilhelm His. Bull. Hist. Med., 74(1):29-79, 2000.

Loukas, M.; Clarke, P.; Tubbs, R. S.; Kapos, T. \& Trotz, M. The His family and their contributions to cardiology. Int. J. Cardiol., 123(2):75-8, 2008.

Mall, F. P. A plea for an institute of human embryology. JAMA, 60(21):1599-601, 1913

Mall, F. P. Wilhelm His. His relation to institutions of learning. Am. J. Anat., 4:139-61, 1905.

O'Rahilly, R. \& Müller, F. The Vesalius of human embryology. Anat. Anz., 166(1-5):245-7, 1988.

Peipert, J. \& Roberts, C. Wilhelm His, Sr.'s finding of Johann Sebastian Bach. Am. J. Cardiol., 57(11):1002, 1986.

Roguin, A. Wilhelm His Jr. (1863-1934) — the man behind the bundle. Heart Rhythm., 3(4):480-3, 2006.
Dirección de correspondencia:

Prof. Carlos Godoy Guzmán

Facultad de Ciencias Médicas

Universidad de Santiago de Chile

Avda. Bdo. O'Higgins 3363, Correo 442

Santiago

CHILE

Tel: 7183523

Fax: 4893465

Email: carlos.godoy@usach.cl

Recibido : 01-10-2012

Aceptado: 04-01-2013 